\title{
Tilt and strain change during the explosion at Minami-dake, Sakurajima, on November 13, 2017
}

Kohei Hotta ${ }^{*^{*}}$ and Masato Iguchi ${ }^{2}$

\begin{abstract}
We herein propose an alternative model for deformation caused by an eruption at Sakurajima, which has been previously interpreted as being due to a Mogi-type spherical point source beneath Minami-dake. On November 13, 2017, a large explosion with a plume height of $4200 \mathrm{~m}$ occurred at Minami-dake. During the $3 \mathrm{~min}$ following the onset of the explosion (November 13, 2017, 22:07-22:10 (Japan standard time (UTC+9); the same hereinafter), phase 1, a large strain with changes up to 120 nstrain was detected at the Arimura observation tunnel (AVOT) located approximately $2.1 \mathrm{~km}$ southeast from the Minami-dake crater. After the peak of the explosion (November 13, 2017, 22:10-24:00), phase 2, a large deflation was detected at every monitoring station due to the continuous Strombolian eruption. Subsidence toward Minami-dake was detected at five out of six stations, whereas subsidence toward the north of Sakurajima was detected at the newly installed Komen observation tunnel (KMT), located approximately $4.0 \mathrm{~km}$ northeast from the Minami-dake crater. The large strain change at AVOT as well as small tilt changes at all stations and small strain changes at the Harutayama observation tunnel (HVOT) and KMT during phase 1 can be explained by a very shallow deflation source beneath Minami-dake at $0.1 \mathrm{~km}$ below sea level (bsl). For phase 2, a deeper deflation source beneath Minami-dake at a depth of $3.3 \mathrm{~km}$ bsl was found in addition to the shallow source beneath Minamidake, which turned inflation after the deflation that occurred during phase 1. However, this model cannot explain the tilt change of KMT. Adding a spherical deflation source beneath Kita-dake at a depth of $3.2 \mathrm{~km}$ bsl can explain the tilt and strain change at KMT and the other stations. The Kita-dake source was also found in a previous study of long-term ground deformation. Not only the deeper Minami-dake source $M_{D}$, but also the Kita-dake source deflated due to the Minami-dake explosion.
\end{abstract}

Keywords: Sakurajima volcano, Spherical source, Dike, Tilt, Strain

\section{Introduction}

The tilt and strain changes accompanying Vulcanian eruptions of Sakurajima have been interpreted as being due to the deflation of a Mogi-type source (Mogi 1958) beneath Minami-dake, because downward tilts associated with eruptions are oriented towards Minami-dake in the underground tunnels Harutayama $(2.7 \mathrm{~km}$ northwest of the Minami-dake crater) and Arimura $(2.1 \mathrm{~km}$

\footnotetext{
*Correspondence: hotta@sus.u-toyama.ac.jp

${ }^{1}$ Faculty of Sustainable Design, University of Toyama, Toyama 930-8555, Japan

Full list of author information is available at the end of the article
}

south-southeast of the crater) (Fig. 1). For the eruptions at Minami-dake starting in 1955, a deflation source was found beneath Minami-dake at a depth of 2-4 km below sea level (bsl), with a deflation volume of $10^{3}-10^{5} \mathrm{~m}^{3}$. This source was also found during an episode of frequent Vulcanian eruptions at Minami-dake that peaked from 1974 to 1992 by precise leveling surveys (Eto 1989). A shallower deflation source was also found at the onset of the eruptions (e.g., Ishihara 1990; Iguchi et al. 2013). For the eruptions at Showa crater starting in 2006, only a shallower deflation source was found beneath Minami-dake at a depth of $0-1.5 \mathrm{~km}$ bsl, with a deflation volume of $10^{2}-10^{4} \mathrm{~m}^{3}$, one-order smaller than that 


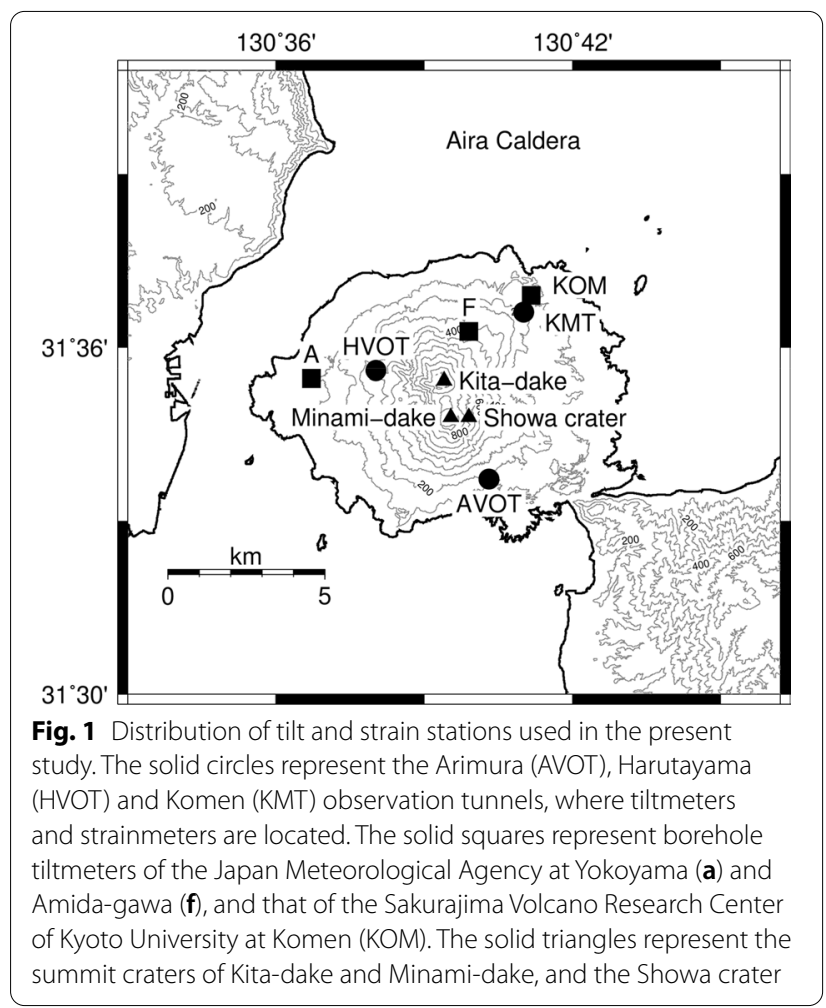

of the Minami-dake eruptions (Iguchi et al. 2013). During an episode of eruptions at the Showa crater, a different source was found beneath Kita-dake at a depth of $3.3 \mathrm{~km}$ bsl by continuous GPS observation data. This source was considered to exhibit repeating inflation and deflation with a period of several years (Hotta et al. 2016a). In August 2016, additional tilt and strain observations were undertaken at a new observation tunnel at Komen, $4.0 \mathrm{~km}$ northeast of Minami-dake, and changes were detected, associated with a large explosion with a plume height of $4200 \mathrm{~m}$ at Minami-dake on November 13, 2017. More than 1 year had passed since installation of tiltmeters and strainmeters in Komen observation tunnel when the eruption occurred. Ground inflation started at 8:00 (Japan standard time (UTC+9); the same hereinafter) on November 7, 2017, which became a gradual deflation on November 11, 2017. When an explosion occurred at 22:07 of November 13, 2017, the gradual deflation became rapid and continued for two hours. The total duration of tilt/strain change of nearly a week is longer than the typical eruptions at Minami-dake in the 1980s of at most $7 \mathrm{~h}$ (Ishihara 1990). The downward tilt direction at the Komen tunnel deviated by $90^{\circ}$ clockwise from the direction of the Minami-dake crater, in a different manner than at the Arimura and Harutayama tunnels, which showed a downward tilt in the direction of the crater. This tilt direction is substantially different from the deformation expected from the inflation of the Mogi-type spherical point source beneath Minami-dake found in previous studies, and thus the deformation at the Komen tunnel is considered to be affected by a different source.

In the present study, we propose a composite source model for tilt and strain changes at ground deformation stations, taking into account the tilt change at the Komen tunnel. We then discuss the magma plumbing system of Sakurajima for a large-scale Vulcanian eruption.

\section{Observations and data}

At Sakurajima, tilt and strain observations have been performed by the Sakurajima Volcano Research Center (SVRC) of Kyoto University; the Osumi Office of River and National Development Bureau, Ministry of Land, Infrastructure, Transport and Tourism of Japan (MLIT); and the Japan Meteorological Agency (JMA). The tilt and strain stations for the present study are distributed as shown in Fig. 1. We used data obtained by watertube tiltmeters and linear strainmeters at the Arimura, Harutayama and Komen underground tunnels (AVOT, HVOT and KMT, respectively) and borehole tiltmeters at Yokoyama, Amida-gawa and Komen (JMA-A, JMA-F and $\mathrm{KOM}$, respectively). The tiltmeters and strainmeters at AVOT, HVOT, KMT and KOM were installed in directions radial and tangential to Minami-dake and the tiltmeters at JMA-A and F were in the north-south and east-west directions. The sensitivities were $0.056 \mathrm{~V} / \mu \mathrm{rad}$ for the water-tube tiltmeters and $0.056 \mathrm{~V} / \mu$ strain for the linear strainmeters. The sensitivity of the borehole tiltmeters was $0.02 \mathrm{~V} / \mu \mathrm{rad}$. The analog-to-digital resolution was 24 bits and the resolution of tilt and strain was $10^{-6}$ nrad.

The tilt and strain changes at AVOT, HVOT and KMT during the period of November 5-14, 2017, are shown in Fig. 2. Upward tilts in the direction of Minami-dake and extension strains started to appear at about 6:00 of November 7 at AVOT and HVOT, whereas a tangential tilt was dominant at KMT. The tilts turned to gradual downward tilts on November 11, 2017. Then, the downward tilt suddenly became rapid at the onset of the explosion on November 13. A deflation tilt change of $283 \mathrm{nrad}$ occurred over two hours at HVOT, which is larger than the tilt changes associated with explosions at Minamidake crater in the previous reports (Ishihara 1990; Tateo and Iguchi 2009).

The tilt and strain changes associated with the explosion are magnified in Fig. 3. In phase 1 (3 min from the onset of the explosion at 22:07), rapid extensions were detected in the radial strains as strain steps. The step at AVOT, the nearest station to the Minami-dake crater, is the largest at 120 nstrain, and the steps are smaller at 


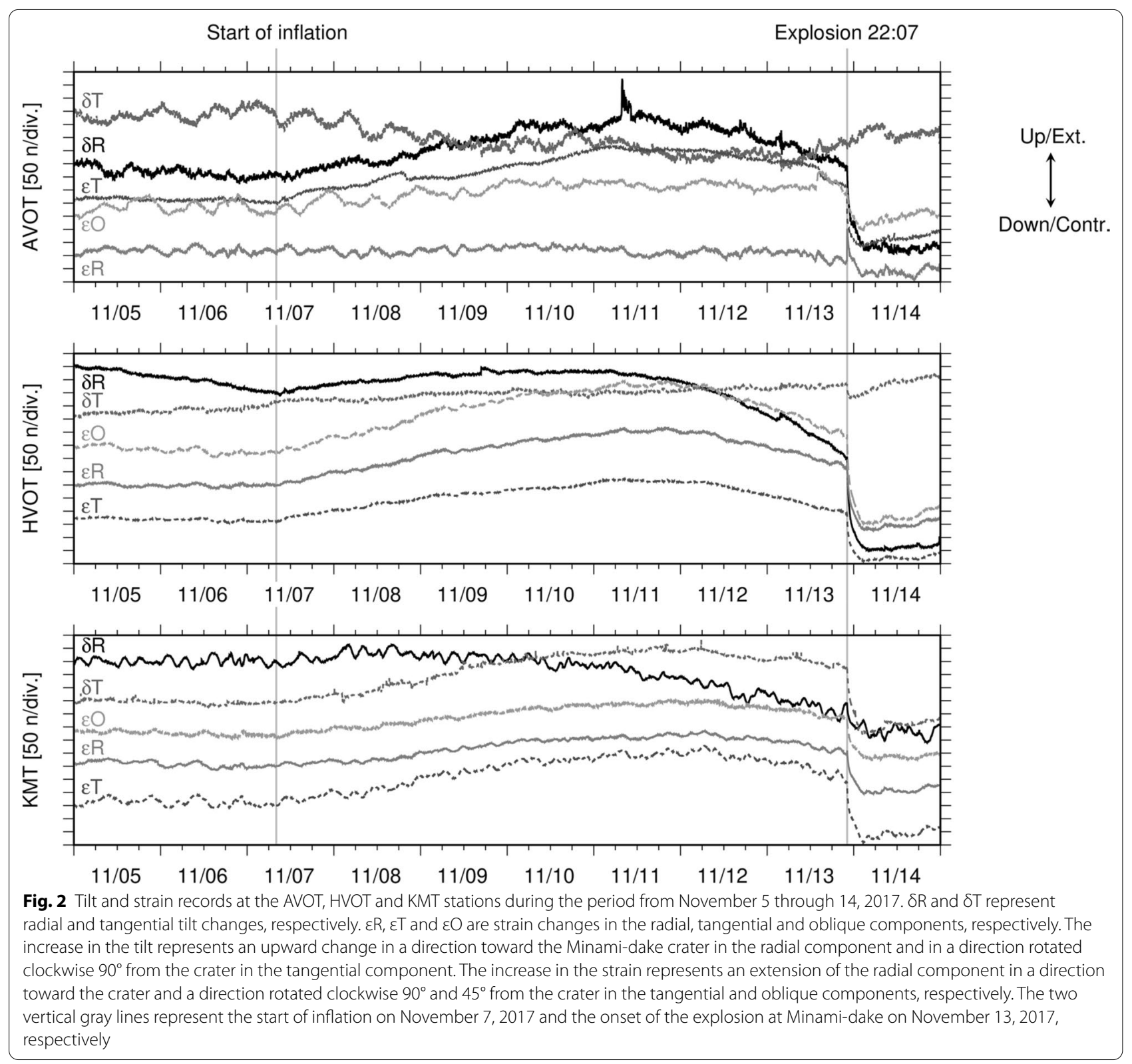

the farther tunnels HVOT and KMT. In phase 2 (22:1024:00), a large deflation with a contraction strain and downward tilts oriented towards the Minami-dake crater are observed, except at KMT. The downward tilt vectors are shown in Fig. 4a. The vector at KMT is oriented toward the north flank of Sakurajima.

\section{Analysis}

\section{Deformation source model}

We applied a finite spherical source (McTigue 1987), a dislocation source (Okada 1992) and a combination of these in a half-infinite homogenous elastic solid. We assumed a Poisson's coefficient of $v=0.25$. Battaglia et al. (2013) obtained the volume change of a spherical source $\Delta V$ by an internal pressure change of $\Delta P$, for a modulus of rigidity $\mu$ and depth and radius of the source $d$ and $a$, respectively, to be

$$
\Delta V=\pi a^{3} \frac{\Delta P}{\mu}\left[1+\left(\frac{a}{d}\right)^{4}\right] .
$$

From Eq. (1), $\Delta P / \mu$ in the equations of deformation by McTigue (1987) can be obtained using $\Delta V$. First-order topographical effects were corrected by adding the elevation of the station to the source depth (Williams and Wadge 1998). The effect of the topography using the finite element method (FEM) is discussed later. 


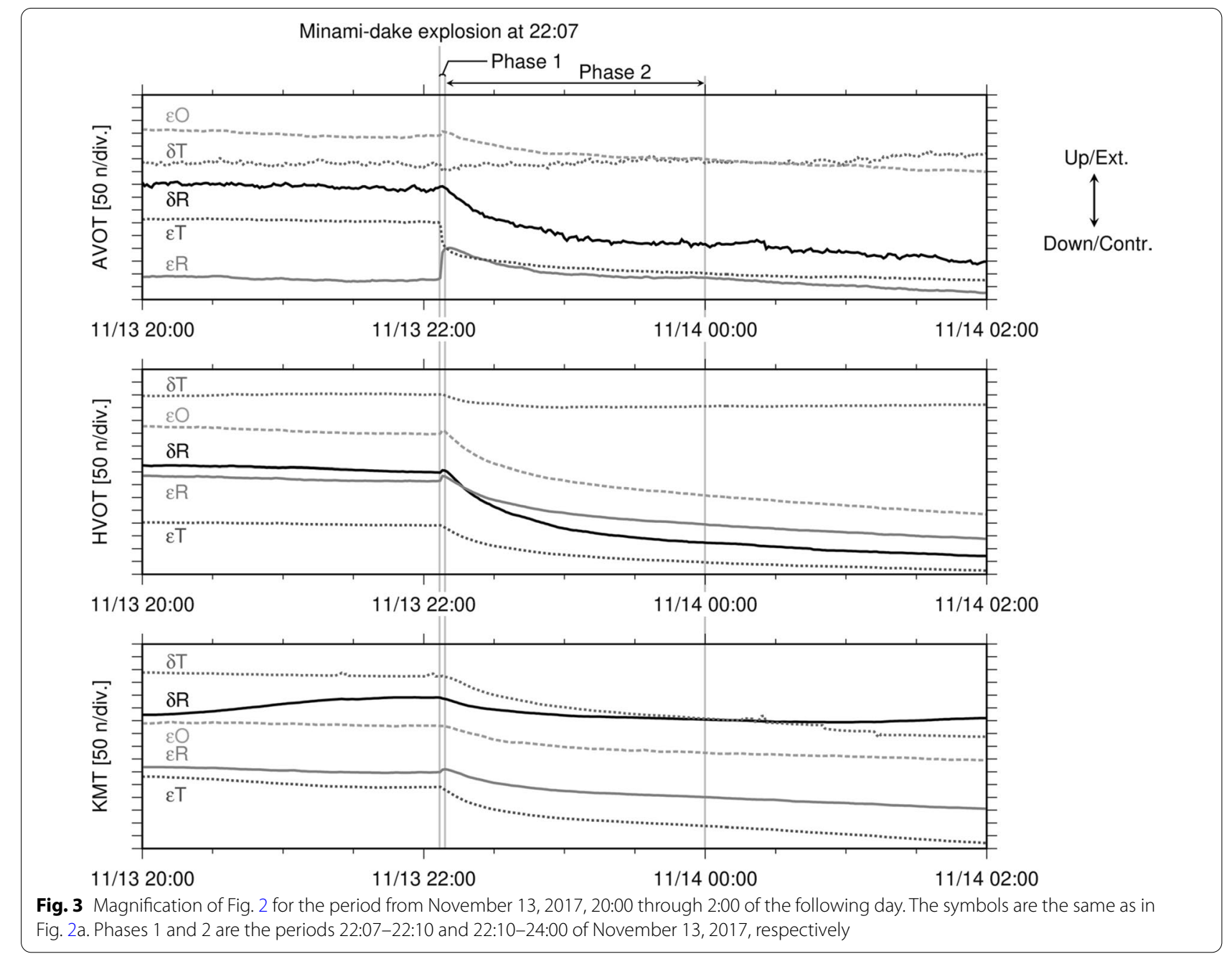

To expand the original elastic source models described above to a multiple-source model, we assumed that the sources do not interact with each other and that the calculated tilt and strain are linear sums of the tilt and strains caused by the sources (Hotta et al. 2016a).

\section{Residual evaluation}

We searched for the optimal parameters for each source (Table 1) using a grid search method. For models with more than seven parameters, i.e., composite model of a tensile fault and dual spherical source, we used a genetic algorithm (e.g., Carroll 1999; Tiampo et al. 2000; Murase et al. 2006) instead of a grid search method. In this case, we set the number of individuals to be 50 ; the probabilities of crossovers, jump mutations and creep mutation to be 70, 2 and 18\%, respectively; and the number of iterations for the genetic algorithm to be 200,000 (Hotta et al. 2016a; b). Here, individuals have model parameter information as binary code; a crossover is a random exchange of part of the binary code among an arbitrary pair of individuals; jump mutation is a random change in a bit in the binary code of an individual; and creep mutation is $a \pm 1$ step change in the model parameter information in an individual. To avoid a local minimum, we executed the iteration process several times (Hotta et al. 2016a, b). To minimize the difference between the observed and theoretical values, we used the weighted residual sum of squares (WRSS):

$$
\mathrm{WRSS}=\Delta^{2}+E^{2},
$$

where $\Delta^{2}$ and $E^{2}$ are weighted residual sums of squares of tilt and strain, respectively:

$$
\Delta^{2}=\sum_{1 \leq i \leq 6}\left[\left(\frac{\delta R_{\mathrm{obs}}^{i}-\delta R_{\mathrm{cal}}^{i}}{\sigma \delta R^{i}}\right)^{2}+\left(\frac{\delta T_{\mathrm{obs}}^{i}-\delta T_{\mathrm{cal}}^{i}}{\sigma \delta T^{i}}\right)^{2}\right],
$$



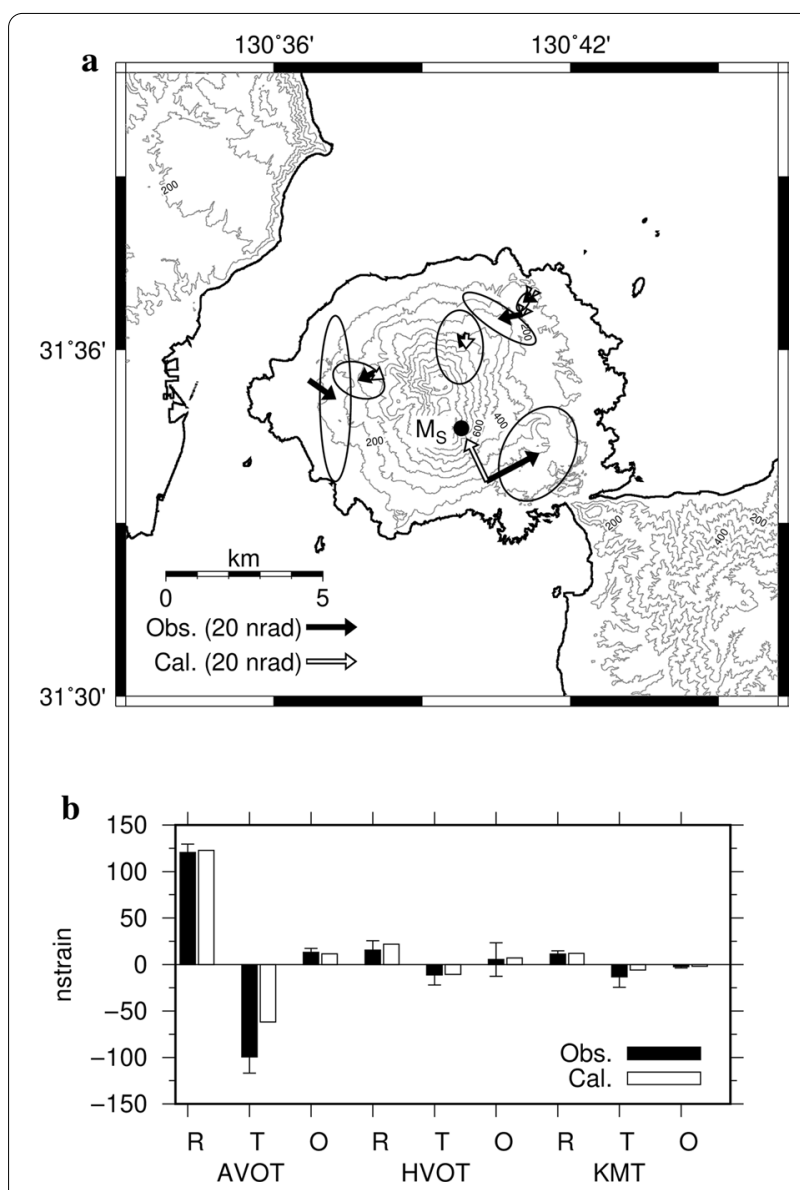

Fig. 4 a Location of the obtained spherical source $\left(M_{s}\right.$, the solid circle) for phase 1 (22:07-22:10) and a comparison of the observed (black) and calculated (white) downward tilts. The error ellipses are 30. The 99\% confidence level estimated by an F-test (Árnadóttir and Segall 1994) is within the size of the solid circle. The depth of the source $M_{S}$ is $0.1 \mathrm{~km}$ bsl. $\mathbf{b}$ Comparison of the observed (black) and calculated (white) radial $(\mathrm{R})$, tangential $(\mathrm{T})$ and oblique $(\mathrm{O})$ extensions. The error bars are 30

\section{Results}

Phase 1

A single spherical source model was determined for phase 1 . Through the grid search method, we obtained a very shallow deflation source beneath Minami-dake (source $\mathrm{M}_{\mathrm{S}}$ ) at $0.1 \mathrm{~km}$ bsl (Fig. 4a, Table 1). Its radius was the minimum value of the search range, $0.1 \mathrm{~km}$. The large strain change detected at AVOT, small tilt change including AVOT and strain change at the other stations can be explained by this source (Fig. 4a and b).

\section{Phase 2 \\ Deformation sources beneath Minami-dake}

During phase 2, subsidence in a direction toward Minami-dake was detected except at the KMT observation tunnel where a subsidence in the direction toward the north flank was detected. Excluding the data of KMT, we applied dual spherical sources: a shallow source (source $M_{\mathrm{S}}$ ) fixed at the location obtained for phase 1 and a deep source, $M_{\mathrm{D}}$. $M_{\mathrm{D}}$ is a deeper $(3.3 \mathrm{~km}$ bsl beneath Minami-dake) deflation source, whereas $\mathrm{M}_{\mathrm{S}}$ causes inflation as shown in Fig. 5a and Table 1. We note, however, that these sources beneath Minami-dake cannot explain the oblique strain change at HVOT. These sources also cannot explain the tilt and strain changes at the KMT observation tunnel, where subsidence toward the north area of Sakurajima was detected (Fig. 5). A significant cause of the difference in tilt change between KMT and $\mathrm{KOM}$, which are spatially located close together, is an additional source. Other causes of the difference may be topography or heterogeneity.

\section{Improvement by the addition of sources for KMT data}

Although the combination of the shallow and deep Minami-dake sources can explain most of the tilt/strain data, there are still misfits in the oblique strain change

$$
E^{2}=\sum_{1 \leq j \leq 3}\left[\left(\frac{\varepsilon R_{\mathrm{obs}}^{j}-\varepsilon R_{\mathrm{cal}}^{j}}{\sigma \varepsilon R^{j}}\right)^{2}+\left(\frac{\varepsilon T_{\mathrm{obs}}^{j}-\varepsilon T_{\mathrm{cal}}^{j}}{\sigma \varepsilon T^{j}}\right)^{2}+\left(\frac{\varepsilon O_{\mathrm{obs}}^{j}-\varepsilon O_{\mathrm{cal}}^{j}}{\sigma \varepsilon O^{j}}\right)^{2}\right]
$$

and where the subscripts obs and cal indicate observed and calculated values; $\delta R^{i}$ and $\delta T^{i}$ indicate the radial and tangential tilt change at the $i$-th tilt station, respectively; $\varepsilon R^{j}, \varepsilon T^{j}$ and $\varepsilon O^{j}$ indicate the radial, tangential and oblique strain changes at the $j$-th observation tunnel, respectively; and $\sigma$ indicates the observation error. The search spaces and step sizes for the parameter estimates are given in Table 1. at HVOT and tilt/strain data at KMT. In the period of 2011-2012, a source was identified beneath Kita-dake (Hotta et al. 2016a), as mentioned in the introduction, and this source may have re-activated during the explosion of Minami-dake. Thus, we add a third source and test whether it was spherical or dike/sill-like.

Triple spherical source model Hotta et al (2016a) found a Mogi-type deformation source beneath Kitadake in addition to that beneath Minami-dake for the 


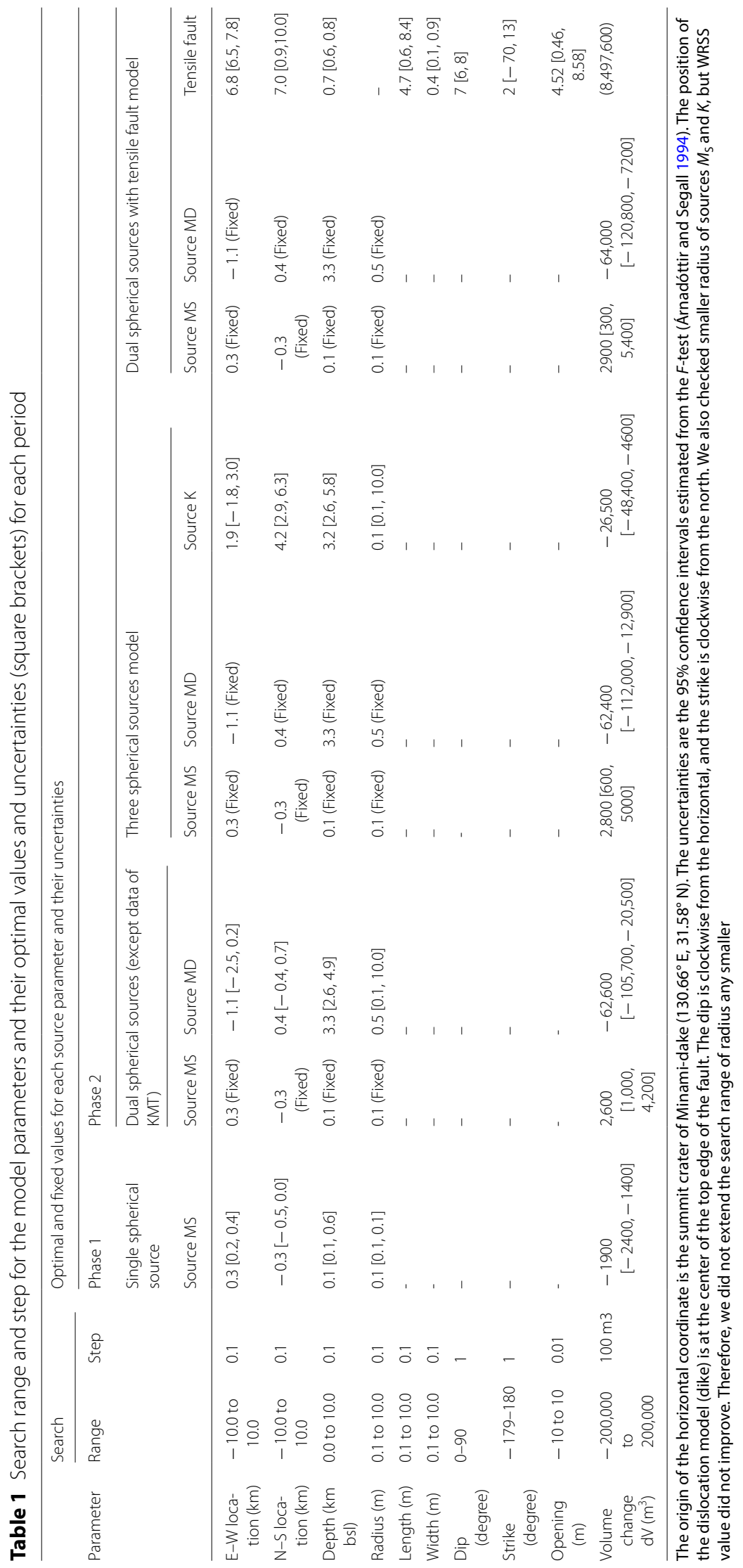



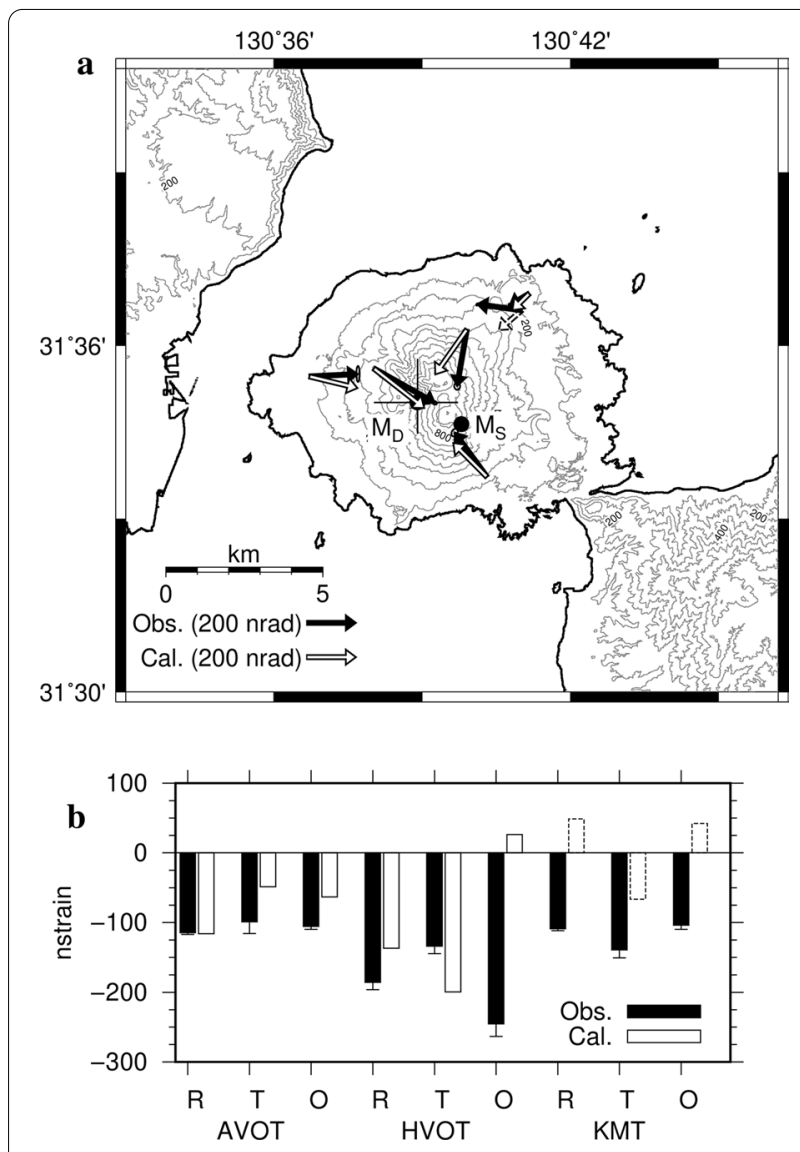

Fig. 5 Same as Fig. 4, but for phase 2 (22:10-24:00), excluding the data of KMT and assuming dual spherical sources (source $M_{S}$ obtained for phase 1 and an additional deeper spherical source $M_{D}$ ). The depths of the sources $M_{S}$ and $M_{D}$ are $0.1 \mathrm{~km}$ bsl and $3.3 \mathrm{~km}$ bsl, respectively. The error bar is the $99 \%$ confidence level estimated by an F-test (Árnadóttir and Segall 1994)

long-term deformation event of October 2011-March 2012. We applied a triple spherical deformation source model adding a spherical source, $K$, beneath Kita-dake. The two original sources, $M_{\mathrm{S}}$ and $M_{\mathrm{D}}$, are fixed in their previously determined locations (Fig. 5), and we solved for the location of the source $\mathrm{K}$ and volume changes of the three sources. The new source is a deflation source beneath the northeast flank of Kita-dake where an inflation source was found by Hotta et al. (2016a) during the long-term deformation period from October 2011 to March 2012 (Fig. 6a; Table 1). The fit of the calculation to the observed oblique strain change at HVOT and tilt and strain changes at KMT are improved by this addition (Fig. 6), and the WRSS value reduced from 55,494 to 13,408 .

Composite model of a tensile fault and dual spherical source Hotta et al. (2016b) applied a tensile fault
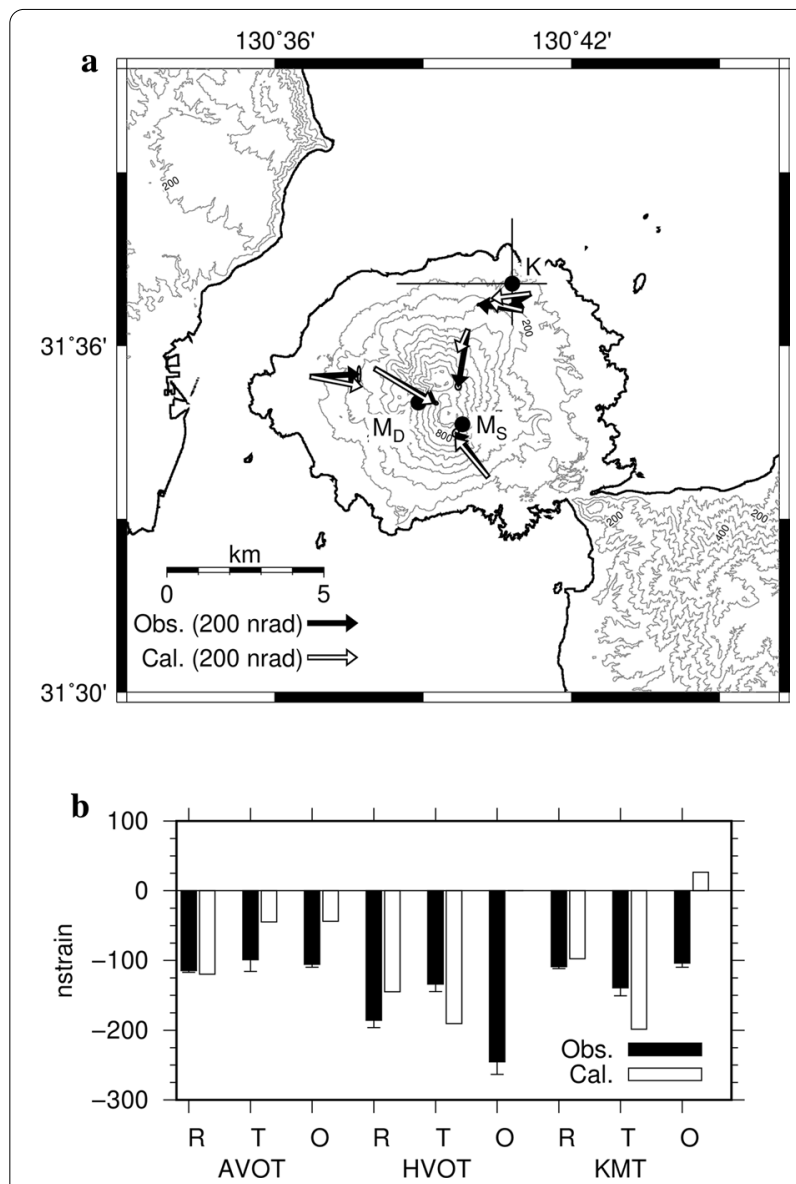

Fig. 6 Same as Fig. 4, but assuming three spherical sources (the dual Minami-dake sources $M_{S}$ and $M_{D}$ and an additional spherical source $K)$ for all the data including KMT. The depths of the sources $M_{S^{\prime}} M_{D}$ and $K$ were $0.1 \mathrm{~km}$ bsl, $3.3 \mathrm{~km}$ bsl and $3.2 \mathrm{~km}$ bsl, respectively

model to the deformation of Sakurajima. Here, we add a tensile fault to $M_{\mathrm{S}}$ and $M_{\mathrm{D}}$. In addition to the inflation of $M_{\mathrm{S}}$ and deflation of $M_{\mathrm{D}}$, a sill with a length and width of 4.7 and $0.4 \mathrm{~km}$, respectively, and striking in the northsouth direction is located beneath northeast off Sakurajima where submarine eruptions occurred around this area during the An'ei eruption in 1779 at a depth of $0.7 \mathrm{~km}$ bsl (Fig. 7a, Table 1). The fit of the calculation to the observed oblique strain change at HVOT and tilt and strain changes at KMT are improved by this addition (Fig. 7), and the WRSS value reduced from 55,494 to $9,140.0$.

\section{Discussion}

Selection of the optimal model for phase 2

To determine the optimal solution, for each model we evaluated the correction of Akaike's Information Criterion (c-AIC) values (Sugiura 1978), which is a finite correction of Akaike's Information Criterion (AIC; Akaike 

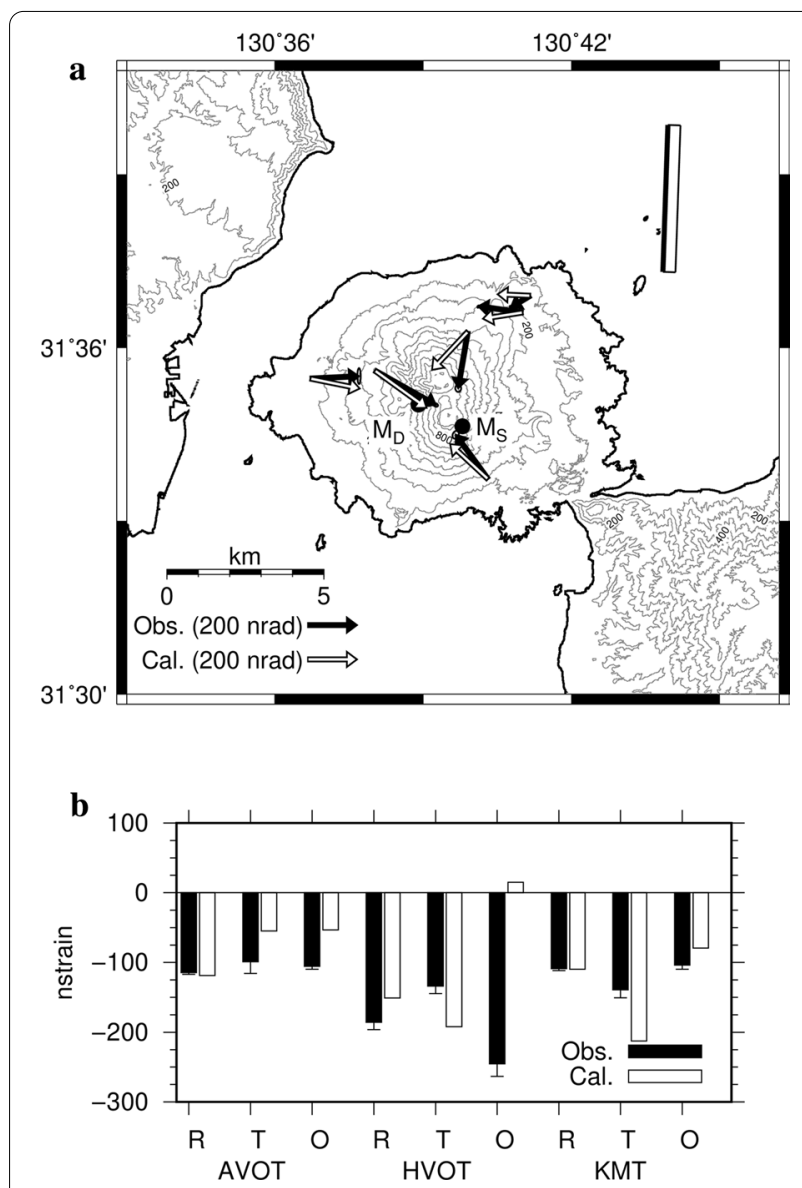

Fig. 7 Same as Fig. 4, but assuming the dual Minami-dake sources $M_{S}$ and $M_{D}$ and an additional dislocation source model (rectangle). The thick black line of the rectangle represents the top of the obtained dislocation source model. The depths of the sources $M_{\mathrm{S}}, M_{\mathrm{D}}$ and the top of the dislocation source are $0.1 \mathrm{~km}$ bsl, $3.3 \mathrm{~km}$ bsl and $0.7 \mathrm{~km}$ bsl, respectively

1973). The WRSS values of the three spherical sources and the dual spherical sources with tensile fault models are 13,408 and 9,140.0, respectively, and the number of free parameters is seven and ten, respectively. These yield c-AIC values of 222.19 and 233.53, respectively. Although the residual is larger than the dual spherical sources with a tensile fault model, the three spherical sources model is better, based on the obtained c-AIC values. In another respect, the volume increase of the obtained tensile fault is nearly $10^{7} \mathrm{~m}^{3}(/ 1.83 \mathrm{~h})$, which is too large based on the typical magma intrusion rate of Sakurajima, $10^{7} \mathrm{~m}^{3} /$ year (Ishihara 1981). The intrusion rate during the inflation period of October 2011-March 2012 was $1.4 \times 10^{7} \mathrm{~m}^{3} /$ year (Hotta et al. 2016a). From GPS observations, a rate as high as $10^{7} \mathrm{~m}^{3}$ in $\sim 2 \mathrm{~h}$ was not detected around the November 13, 2017 Minami-dake explosion, as shown in Fig. 8, indicating that the intrusion rate at this time was less than on the order of $10^{7} \mathrm{~m}^{3} /$ year. Therefore, we concluded that the three spherical sources model is the optimal model for phase 2 .

As for a finite spherical source model, Pascal et al. (2014) noted that the effects of interactions between sources are negligible when the sources are separated by four or more radii. The distance between sources $M_{\mathrm{S}}$ and $M_{\mathrm{D}}$ is $3.6 \mathrm{~km}$, that between $M_{\mathrm{D}}$ and $K$ is $4.8 \mathrm{~km}$, and that between $K$ and $M_{\mathrm{S}}$ is $5.7 \mathrm{~km}$. Meanwhile, the optimal radii of $M_{\mathrm{S}}, M_{\mathrm{D}}$ and $\mathrm{K}$ are $0.1 \mathrm{~km}, 0.5 \mathrm{~km}$ and $0.1 \mathrm{~km}$, respectively. From these distances and radii, these three spherical sources are separated enough to ignore the effects of interactions between them.

\section{Interpretations of the sources}

During the $3 \mathrm{~min}$ from the onset of the explosion at 22:07, phase 1, a very shallow deflation source was obtained beneath Minami-dake, similar to previous eruptions at the Minami-dake (Ishihara 1990) and Showa craters (Iguchi et al. 2013). This means that the deflation starts from a shallow part of the magma plumbing system of Sakurajima. This shallow source might represent the uppermost part of the magma conduit from a deeper Minami-dake source to the summit crater, which has been interpreted as a high-pressure gas chamber (e.g., Iguchi 1994). After the peak of the Vulcanian eruption, phase 2, the deeper source beneath Minamidake deflated while the shallower source inflated. The deep deflation source beneath Minami-dake had been identified based on tilt and strain changes during previous eruptions at the Minami-dake and Showa craters. The obtained depth of $3.3 \mathrm{~km}$ bsl was comparable with previous studies $(2-4 \mathrm{~km})$, and the horizontal location of the source was similar to the fixed location beneath Minami-dake of previous studies (e.g., Ishihara 1990; Iguchi et al. 2013). In addition to the deeper source, inflation of the shallower source was detected. The shallow inflation source beneath Minami-dake found in the present study was not found in the previous studies. During the Minami-dake eruption including this event, the shallower source is considered to deflate for the first phase of each eruption. In this event, the shallower source inflated after the peak of the explosion probably because the amount of accumulated magma from the deeper source exceeded that of the emission from the Minami-dake crater due to continuous Strombolian eruptions (Fig. 9). In addition to the two Minami-dake sources, we found a deflating spherical source at a depth of $3.2 \mathrm{~km}$ bsl at the northeastern flank of Kita-dake. The Kita-dake source might correspond to the source $K$ found beneath Kita-dake at a depth of $3.3 \mathrm{~km}$ bsl from a combination analysis of GPS, tilt and strain data during the period from October 2011 to March 2012 (Hotta et al. 2016a). The Kita-dake source was also found based on vertical displacement during 


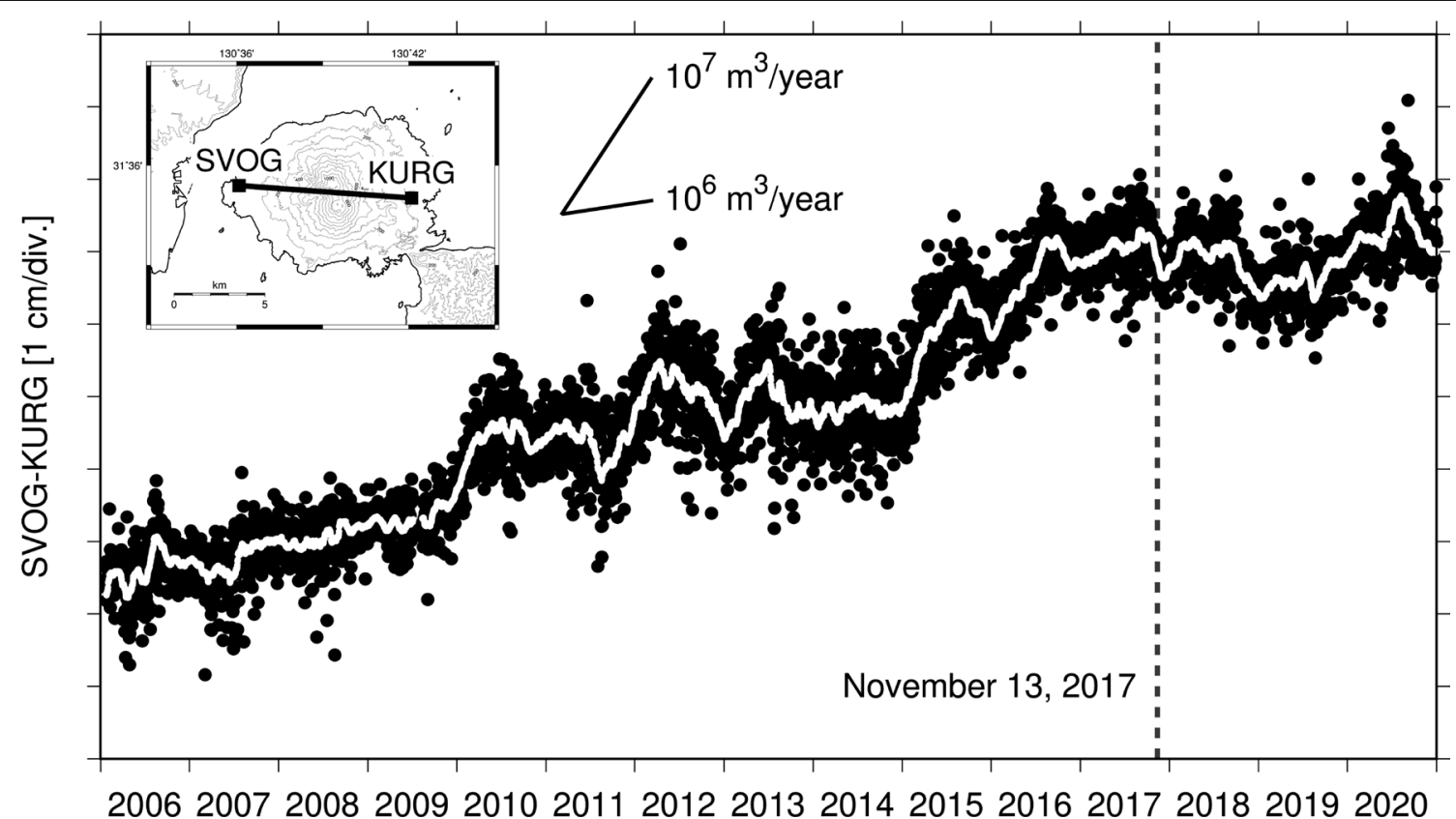

Fig. 8 Change in horizontal distance between GPS stations SVOG and KURG during the period from 2006 to 2020. The gray dashed line represents November 13, 2017. The offset due to dike intrusion on August 15, 2015 (Hotta et al. 2016b) was removed. The white line represents a 30-day rolling average trendline. The intrusion rate and corresponding slope of displacement indicated by the lines on the right side of the map is based on the intrusion rate during the inflation period of October 2011-March $2012\left(1.4 \times 10^{7} \mathrm{~m}^{3} /\right.$ year; Hotta et al. 2016a) and the assumption that the intrusion rate and the deformation rate are linearly related.

Phase $1(22: 07-22: 10)$

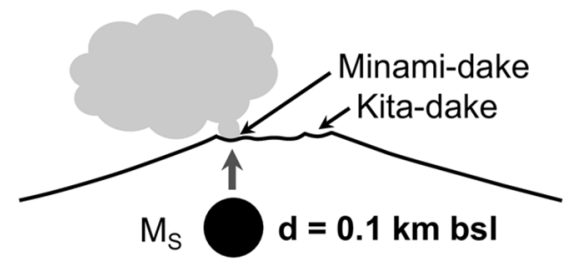

Phase 2 (22:10-24:00)

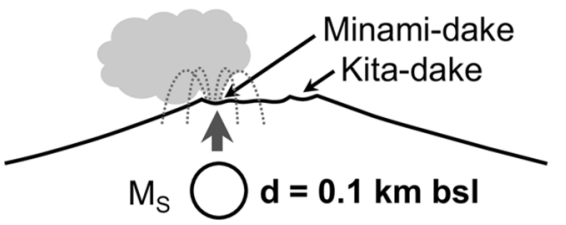

$\mathrm{d}=3.3 \mathrm{~km}$ bs

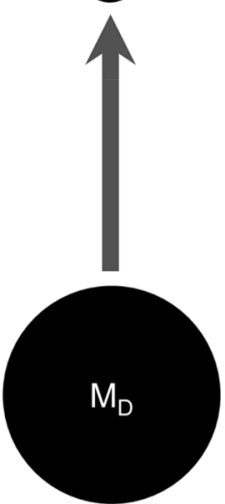

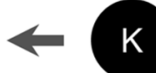

K $\mathrm{d}=3.2 \mathrm{~km}$ bsl

Fig. 9 Schematic diagrams of magma migration during the Minami-dake explosion revealed in the present study. The left diagram represents phase 1 (22:07-22:10) and the right represents phase 2 (22:10-24:00). The open and solid circles represent inflation and deflation of the spherical sources, respectively. The thickness of the arrows between each source or the Minami-dake crater represents the amount of magma migration based on the assumption that uncompressible magma migrates from sources $\mathrm{K}$ to $M_{\mathrm{D}}, M_{\mathrm{D}}$ to $M_{\mathrm{S}}$, and $M_{\mathrm{S}}$ to Minami-dake crater, and magma is not injected towards source K 
the period from November 2008 to November 2009, obtained from a precise leveling survey (Yamamoto et al. 2013). Not only the deeper Minami-dake source $M_{D}$ but also the Kita-dake source deflated due to the Minamidake explosion (Fig. 9). The total deflation volume of sources $M_{\mathrm{D}}$ and $K$ was $88,900 \mathrm{~m}^{3}$, which is comparable with the previous Minami-dake eruptions of $10^{3}-10^{5} \mathrm{~m}^{3}$ (Ishihara 1990).

A clear reflector at a depth of $5.8 \mathrm{~km}$ bsl beneath Kitadake, identified as an overcritical PP reflection, was found by seismic experiments during the period from December 2009 to December 2014. The reflection became clear in December 2014, and the reflector was interpreted as a sill (Tsutsui et al. 2016). The source $\mathrm{K}$ obtained in the present study is shallower than the reflector, but the horizontal location is similar. The $99 \%$ confidence interval of the depth of source $K$ is $2.6-5.8 \mathrm{~km}$ bsl, as shown in Table 1 , and the depths of source $K$ and the reflector may overlap considering the uncertainty in the depth of the reflector of $\pm 90 \mathrm{~m}$ (Tsutsui, personal communication on December 17, 2020). If source $K$ and the reflector are the same, the difference in the optimal depth may be due to the source shape, such as a penny shaped source (Fialko et al. 2001), or heterogeneity, which we will discuss for volume changes later. These should be considered closely in future studies.

Recent studies on magma plumbing systems (e.g., Cashman et al. 2017) indicate that magma recharge of upper crustal reservoirs, where silicic melts segregate from mafic magma, grow large magma bodies and become a trigger for eruptions. The mafic magma is intermittently resupplied from deeper levels in the system. As for Sakurajima, mafic magma has been frequently injected since the twentieth century (Nakagawa et al. 2011). The intrusion rate from the Aira caldera to the Kita-dake source is up to $500 \mathrm{~m}^{3} /$ day during inflation periods (Hotta et al. 2016a) when the $\mathrm{SiO}_{2}$ content of volcanic glass decreases, which indicates the injection of mafic magma (Matsumoto et al. 2013). This causes inflation of the Kita-dake source, which acts as a buffer for increases in eruptive activity (Hotta et al. 2016a), becoming a trigger of magma migration to deeper and shallower Minami-dake sources. As a result, magma is finally emitted from the Minami-dake or Showa crater, causing eruptions.

\section{Effect of topography and heterogeneity}

There are many limitations such as topography and heterogeneity in the homogeneous analytical model we used in the present study (e.g., Del Negro et al. 2009; Gottsmann and Odbert 2014; Hickey et al. 2016; Hotta and Iguchi, 2017). Although realistic modeling using FEM is time consuming, we checked for the effect of volume change for phase 2. We applied the FEM using Flex PDE Professional software version 6.50 provided by PDE Solutions Inc. We set an FEM domain size of $100 \times 100 \times 50$ $\mathrm{km}^{3}\left(130.13325-131.18675^{\circ}\right.$ E, 31.12906-32.03094 $\mathrm{N}$, $0-50 \mathrm{~km} \mathrm{bsl}$ ). The maximum grid size was set to be 30 per $100 \mathrm{~km}$ and the grid size in the domain was set automatically by the software. We set the top of the domain to be a free surface, and the sides and bottom of the domain to be fixed boundaries. Topography was introduced in the area within Sakurajima using digital elevation model (DEM) data with $100 \mathrm{~m}$ resolution, and the elevation of the outside area was assumed to be sea level. Heterogeneity of the P-wave velocity was introduced referring to Miyamachi et al. (2013), as 1, 2.5, 3.6, 4.8 and $6 \mathrm{~km} / \mathrm{s}$ for the depth ranges of $0-0.2,0.2-1,1-2,2-3$ and $3+\mathrm{km}$ from the surface, respectively, as shown in Fig. 10. Assuming a Poisson's ratio of 0.25 and $V_{\mathrm{P}} / V_{\mathrm{S}}$ velocity ratio of 1.73 (e.g., Hotta et al. 2016b), the modulus of rigidity $\mu$ can be written using the density of ground $\rho$ as

$$
\mu=\frac{\rho V_{\mathrm{P}}^{2}}{3}
$$

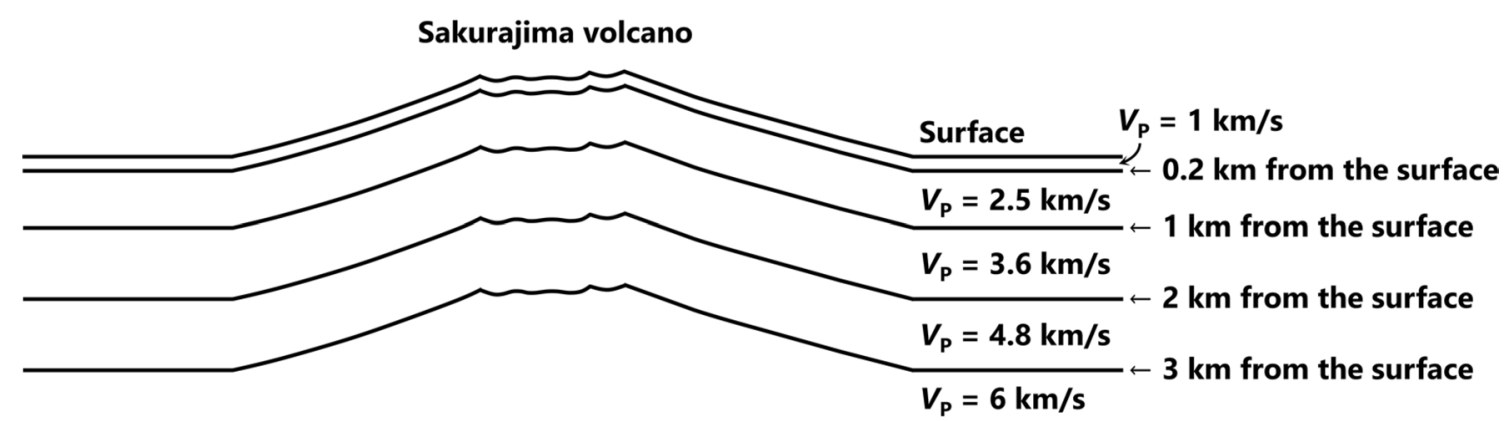

Fig. 10 Schematic description of P-wave velocity structure introduced in the finite element method in "Effect of topography and heterogeneity" section 
Currenti et al. (2007) found the following empirical formula between the density of the ground and P-wave velocity:

$$
\rho=1.2861+0.5498 V_{\mathrm{P}}-0.0930 V_{\mathrm{P}}^{2}+0.007 V_{\mathrm{P}}^{3} .
$$

From Eqs. (5) and (6), the modulus of rigidity of the P-wave velocity structure can be calculated to be 1.02 , $3.99,6.84,10.5$ and $15.1 \mathrm{GPa}$ for the depth ranges of $0-0.2,0.2-1,1-2,2-3$ and $3+\mathrm{km}$ from the surface, respectively. Using the FEM domain described above, we first calculated the tilt and strain change due to a pressure change of $+1 \mathrm{MPa}$ inside each source $\left(M_{\mathrm{S}}, M_{\mathrm{D}}\right.$ and $K$ ) while fixing the horizontal location, depth and radius that were obtained using a homogeneous analytical model. We then searched for the optimal internal pressure change by a grid search method based on the fact that tilt/strain changes are proportionate to internal pressure changes in FEM calculations. The search range and step were set to be $-100-+100 \mathrm{MPa}$ and $0.01 \mathrm{MPa}$, respectively. The optimal internal pressure changes of $\mathrm{M}_{\mathrm{S}}, \mathrm{M}_{\mathrm{D}}$ and $\mathrm{K}$ were $+0.71 \mathrm{MPa},-1.41 \mathrm{MPa}$ and $-82.98 \mathrm{MPa}$, respectively. These yielded volume changes of $+450 \mathrm{~m}^{3},-36,200 \mathrm{~m}^{3}$ and $-16,700 \mathrm{~m}^{3}$, respectively. The yielded WRSS value of 15,997 was slightly larger than that of our homogeneous analytical model, but the data can be well explained (Fig. 11). All of the yielded volume change amounts were smaller than those obtained using a homogeneous analytical model, especially that for the shallowest source $\mathrm{M}_{\mathrm{S}}$, the result for which $\left(+450 \mathrm{~m}^{3}\right)$ was outside of the estimated 99\% confidence interval of the homogeneous analytical model $\left(600-5000 \mathrm{~m}^{3}\right)$. This indicates that modeling by a homogeneous analytical model overestimates of the volume change, particularly for the shallow source. The weight of ashfall in November 2017 is estimated to be $1.75 \times 10^{8} \mathrm{~kg}$. Although six eruptions occurred in November 2017, five eruptions excepting that on November 13, 2017, were extremely small-scale (plume heights were not exceeding $2000 \mathrm{~m}$ ). Therefore, the weight of ashfall by the November 13, 2017 Minami-dake explosion can be assumed to be nearly $1.75 \times 10^{8} \mathrm{~kg}$. Assuming a dense rock equivalent (DRE) density of $2500 \mathrm{~kg} / \mathrm{m}^{3}$, the volume of ejected magma is nearly $70,000 \mathrm{~m}^{3}$. Since the total deflation volume of sources $M_{D}$ and $K$ from FEM analysis was $52,900 \mathrm{~m}^{3}$ and the inflation of the source $\mathrm{M}_{\mathrm{S}}$ is very small (450 $\mathrm{m}^{3}$ ), magma was compressed by up to $25 \%$ in these deep sources. The pressure change value of the source $K$ is very large. In addition, the $95 \%$ confidence interval of the radius of source $K$ is $0.1-10 \mathrm{~km}$. This result indicates that the radius of the source $K$ can be larger than $0.1 \mathrm{~km}$ and therefore the pressure change value would be smaller.
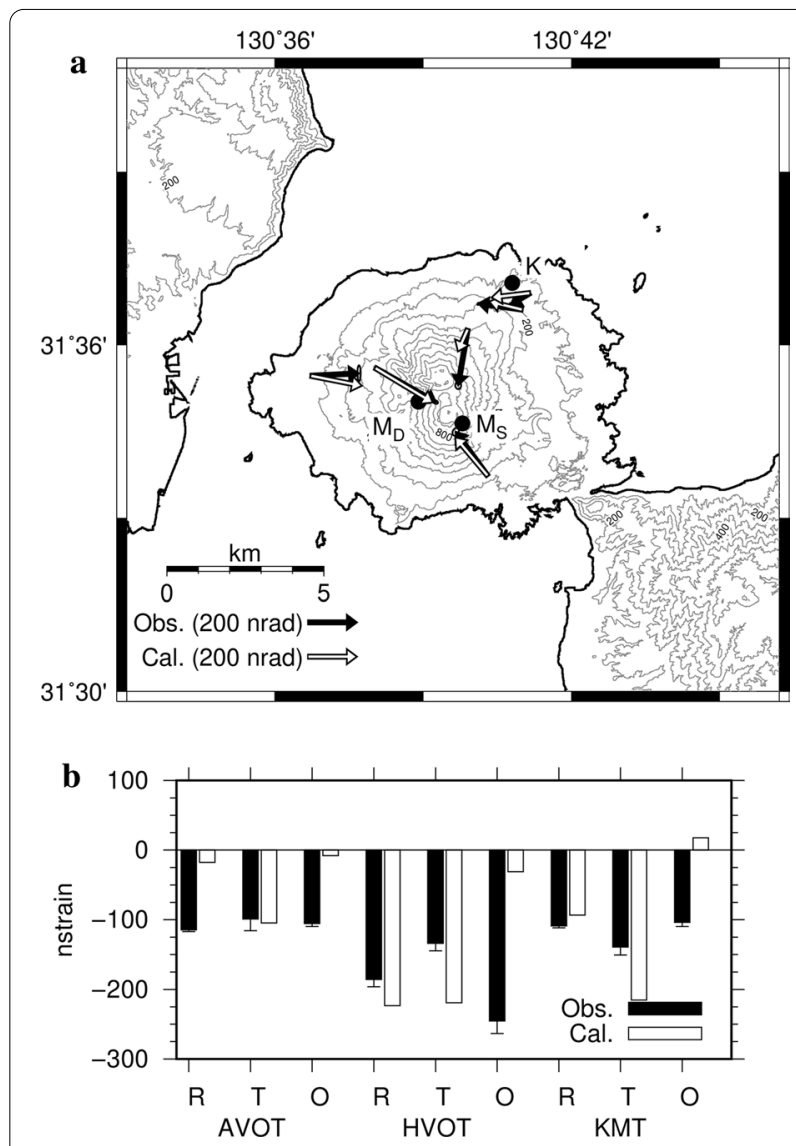

Fig. 11 Same as Fig. 6, but for the analysis using the finite element method in "Effect of topography and heterogeneity" section

In this study, we checked only for volume change. The location, depth and radius of the source should be investigated in a future study.

\section{Conclusions}

We modeled the tilt and strain change during the eruption at Minami-dake on November 13, 2017 by an elastic model. During the $3 \mathrm{~min}$ from the onset of the explosion at 22:07, a shallow source beneath Minami-dake was deflated, which was interpreted as the uppermost part of a magma conduit from the deeper Minami-dake source to the summit crater. After the peak of the Vulcanian eruption, the deeper source beneath Minami-dake deflated while the shallower source inflated. The deep deflation source beneath Minami-dake had been identified based on tilt and strain changes during previous eruptions at the Minami-dake and Showa craters. Inflation of the shallower source may be caused by accumulated magma from the deeper source exceeding that of the emission from the Minami-dake crater due to continuous Strombolian eruptions. In addition, a deflating spherical source beneath Kita-dake was also found, which 
was identified during the long-term deformation event in 2011-2012. We found that the Kita-dake source, which was considered to be in a cycle of inflation and deflation with a period of several years, may also cause deformation during each eruption.

\section{Abbreviations}

bsl: Below sea level; SVRC: Sakurajima Volcano Research Center; MLIT: Ministry of Land, Infrastructure, Transport and Tourism of Japan; JMA: Japan Meteorological Agency; c-AIC: Correction of Akaike's Information Criterion; AIC: Akaike's Information Criterion; GPS: Global Positioning System; DEM: Digital elevation model; DRE: Dense rock equivalent.

\section{Acknowledgements}

We used tilt and strain data from the AVOT station and DEM data from the Osumi Office of River and National Highway, Kyushu Regional Development Bureau, MLIT; tilt data from the JMA; and the program code of Dr. Carroll's FORTRAN genetic algorithm driver (Carroll, 1999). Some of the figures in this paper were prepared using generic mapping tools (Wessel et al. 2013). We would like to thank Drs. Sagiya and Hickey and an anonymous reviewer for their helpful comments.

\section{Authors' contributions}

$\mathrm{KH}$ contributed to the study conception and design; acquisition, analysis and interpretation of the data; and drafted the manuscript. Ml contributed to the study conception and design; acquisition and analysis of data; and helped to draft the manuscript with critical revisions. Both authors read and approved the final manuscript.

\section{Funding}

This study was supported by the Ministry of Education, Culture, Sports, Science and Technology (MEXT) of Japan, under its Earthquake and Volcano Hazards Observation and Research Program, and was a consignment study from the Ministry of Land, Infrastructure, Transport and Tourism of Japan (MLIT).

\section{Availability of data and materials}

The datasets supporting the conclusions of this article are included within the article.

\section{Declarations}

\section{Ethics approval and consent to participate}

Not applicable.

\section{Consent for publication}

Not applicable.

\section{Competing interests}

The authors declare that they have no competing interests.

\section{Author details}

1 Faculty of Sustainable Design, University of Toyama, Toyama 930-8555, Japan.

${ }^{2}$ Sakurajima Volcano Research Center, Disaster Prevention Research Institute,

Kyoto University, Kagoshima 891-1419, Japan.

Received: 11 November 2020 Accepted: 2 March 2021

Published online: 16 March 2021

\section{References}

Akaike H (1973) Maximum likelihood identification of Gaussian autoregressive moving average model. Biometrika 60(2):255. https://doi. org/10.2307/2334537

Árnadóttir T, Segall P (1994) The 1989 Loma Prieta earthquake imaged from inversion of geodetic data. J Geophys Res 99(B11):21835-21855. https:// doi.org/10.1029/94JB01256
Battaglia M, Cervelli PF, Murray JR (2013) Modeling crustal deformation near active faults and volcanic centers-a catalog of deformation models. USGS Numbered Series, Tech Methods 13:B1. https://doi.org/10.3133/ tm13B1

Carroll DL (1999) FORTRAN genetic algorithm (GA) driver. http://www.cuaer ospace.com/Technology/GeneticAlgorithm/GADriverFreeVersion.aspx. Accessed 7 June 2020.

Cashman KV, Sparks RSJ, Blundy JD (2017) Vertically extensive and unstable magmatic systems: a unified view of igneous processes. Science 355(6331):eaag3055. https://doi.org/10.1126/science.aag3055

Currenti G, Del Negro C, Ganci G (2007) Modeling o ground deformationand gravity fields using finite element method: an application to Etna volcano. Geophys J Int 169:775-786. https://doi.org/10.1111/j.1365246X.2007.03380.x

Del Negro C, Currenti G, Scandura D (2009) Temperature-dependent viscoelastic modeling of ground deformation: application to Etna volcano during the 1993-1997 inflation period. Phys Earth Planet Inter 172:299-309. https://doi.org/10.1016/j.pepi.2008.10.019

Eto K (1989) Ground deformation at Sakurajima and around Aira caldera associated with the volcanic activity. Ann Disaster Prev Res Inst Kyoto Univ 32(1):29-39 (in Japanese with English abstract)

Fialko Y, Khazan Y, Simons M (2001) Deformation due to a pressurized horizontal circular crack in an elastic half-space, with applications to volcano geodesy. Geophys J Int 146:181-190. https://doi.org/10.1046/j.1365246X.2001.00452.x

Gottsmann J, Odbert H (2014) The effects of thermomechanical heterogeneities in island arc crust on time-dependent preeruptive stresses and the failure of an andesitic reservoir. J Geophys Res Solid Earth 119:4626-4639. https://doi.org/10.1002/2014JB011079

Hickey J, Gottsmann J, Nakamichi H, Iguchi M (2016) Thermomechanical controls on magma supply and volcanic deformation: application to Aira caldera. Japan Sci Rep 6:32691

Hotta K, Iguchi M (2017) Ground deformation source model at Kuchinoerabujima volcano during 2006-2014 as revealed by campaign GPS observation. Earth, Planets and Space 69:173. https://doi.org/10.1186/s4062 3-017-0763-7

Hotta K, Iguchi M, Ohkura T, Yamamoto K (2016a) Multiple-pressure-source model for ground inflation during the period of high explosivity at Sakurajima volcano, Japan - Combination analysis of continuous GNSS, tilt and strain data -. J Volcanol Geotherm Res 310:12-25. https://doi. org/10.1016/j.jvolgeores.2015.11.017

Hotta K, Iguchi M, Tameguri T (2016b) Rapid dike intrusion into Sakurajima volcano on August 15, 2015, as detected by multi-parameter ground deformation observations. Earth Planets Space 68:68. https://doi. org/10.1186/s40623-016-0450-0

Iguchi M (1994) A vertical expansion source model for the mechanisms of earthquakes originated in the Magma Conduit of an Andesitic Volcano: Sakurajima, Japan. Bull Volcanol Soc Japan 39(2):49-67. https://doi. org/10.18940/kazan.39.2_49

Iguchi M, Tameguri T, Ohta Y, Ueki S, Nakao S (2013) Characteristics of volcanic activity at Sakurajima Volcano's Showa crater during the period 2006 to 2011. Bull Volcanol Soc Japan 58(1):115-135. https://doi.org/10.18940/ kazan.58.1 115

Ishihara K (1981) A quantitative relation between the ground deformation and the volcanic materials ejected. Abstract 1981 IAVCEI Symposium - Arc Volcanism, 143

Ishihara K (1990) Pressure sources and induced ground deformation associated with explosive eruptions at an andesitic volcano: Sakurajima volcano, Japan. Magma transport and storage (Ed. M.P. Ryan), John Willey and Sons, 335-356.

Matsumoto A, Nakagawa M, Miyasaka M, Iguchi M (2013) Temporal variation of the petrological features of the juvenile materials during 2006 to 2010 from Showa Crater, Sakurajima Volcano Japan. Bull Volcanol Soc Japan 58(1):191-212. https://doi.org/10.18940/kazan.58.1_191

McTigue DF (1987) Elastic stress and deformation near a finite spherical magma body: resolution of the point source paradox. J Geophys Res 92(B12):12031-12940. https://doi.org/10.1029/JB092iB12p12931

Miyamachi H, Tomari C, Yakiwara H, Iguchi M, Tameguri T, Yamamoto K, Ohkura T, Ando T, Onishi K, Shimizu H, Yamashita Y, Nakamichi H, Yamawaki T, Oikawa J, Ueki S, Tsutsui T, Mori H, Nishida M, Hiramatsu H, Koeda T, Masuda Y, Katou K, Hatakeyama K, Kobayashi T (2013) Shallow velocity 
structure beneath the Aira Caldera and Sakurajima Volcano as inferred from refraction analysis of the seismic experiment in 2008. Bull Volcanol Soc Japan 58(1):227-237. https://doi.org/10.18940/kazan.58.1_227

Mogi K (1958) Relations between the eruptions of various volcanoes and the deformations of the ground surfaces around them. Bull Earthq Res Inst Univ Tokyo 36:99-134

Murase M, Irwan M, Kariya S, Tabei T, Okuda T, Miyajima R, Oikawa J, Watanabe H, Kato T, Nakao S, Ukawa M, Fujita E, Okayama M, Kimata F, Fujii N (2006) Time dependent model of magma intrusion in and around Miyake and Kozu Islands, Central Japan in June-August, 2000. Volcanol Geotherm Res 150:213-231. https://doi.org/10.1016/j.jvolgeores.2005.02.005

Nakagawa M, Matsumoto A, Miyasaka M, Togashi Y, Iguchi M (2011) Change of made of eruptive activity and the magma plumbing system of Sakurajima Volcano since the 20th century. In Study on preparation process of volcanic eruption based on integrated volcano observation 2010, Sakurajima Volcano Research Center, 85-94 (in Japanese with English abstract).

Okada Y (1992) Internal deformation due to shear and tensile faults in a half space. Bull Seismol Soc Am 82(2):1018-1040

Pascal K, Neuberg J, Rivalta E (2014) On precisely modelling surface deformation due to interacting magma chambers and dikes. Geophys J Int 196:253-278. https://doi.org/10.1093/gji/ggt343

Sugiura N (1978) Further analysis of the data by Akaike's information criterion and the finite corrections. Commun Stat Theory Methods 7(1):13-26. https://doi.org/10.1080/03610927808827599

Tateo Y, Iguchi M (2009) Ground deformation associated with BL-type earthquake swarms at Sakurajima Volcano. Bulletin of Volcanological Society of Japan 54(4):175-186 (in Japanese with English abstract)
Tiampo KF, Rundle JB, Fernandez J, Langbein JO (2000) Spherical and ellipsoidal volcanic sources at Long Valley caldera, California, using a genetic algorithm inversion technique. J Volcanol Geotherm Res 102:189-206. https://doi.org/10.1016/S0377-0273(00)00185-2

Tsutsui T, Iguchi M, Tameguri T, Nakamichi H (2016) Structural evolution beneath Sakurajima Volcano, Japan, revealed through rounds of controlled seismic experiments. J Volcanol Geoth Res 315:1-14. https://doi. org/10.1016/j.jvolgeores.2016.02.008

Wessel P, Smith WHF, Scharroo R, Luis JF, Wobbe F (2013) Generic mapping tools: improved version released. EOS Trans Am Geophys Union 94:409-410. https://doi.org/10.1002/2013EO450001

Williams CA, Wadge G (1998) The effects of topography on magma chamber deformation models: application to Etna and radar interferometry. Geophys Res Lett 25(10):1549-1552. https://doi.org/10.1029/98GL01136

Yamamoto K, Sonoda T, Takayama T, Ichikawa N, Ohkura T, Yoshikawa S, Hiroyuki I, Matsushima T, Uchida K, Nakamoto M (2013) Vertical ground deformation associated with the volcanic activity of Sakurajima volcano, Japan during 1996-2010 as revealed by repeated precise leveling surveys. Bull Volcanol Soc Japan 58(1):137-151

\section{Publisher's Note}

Springer Nature remains neutral with regard to jurisdictional claims in published maps and institutional affiliations.

\section{Submit your manuscript to a SpringerOpen ${ }^{\circ}$ journal and benefit from:}

- Convenient online submission

$\checkmark$ Rigorous peer review

- Open access: articles freely available online

- High visibility within the field

Retaining the copyright to your article

Submit your next manuscript at $\boldsymbol{\nabla}$ springeropen.com 